Workplace Safety and Health

\title{
VIOLENCE
}

\section{Occupational Hazards} in Hospitals

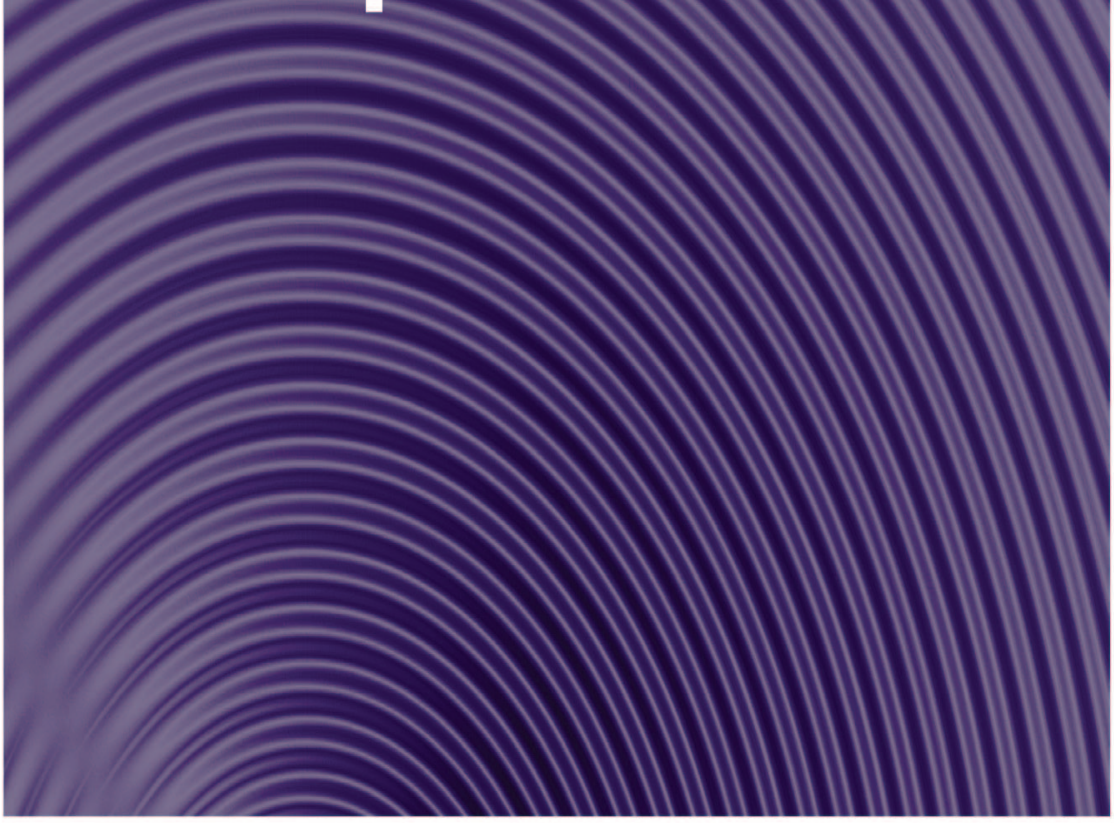

DEPARTMENT OF HEALTH AND HUMAN SERVICES

Centers for Disease Control and Prevention

National Institute for Occupational Safety and Health

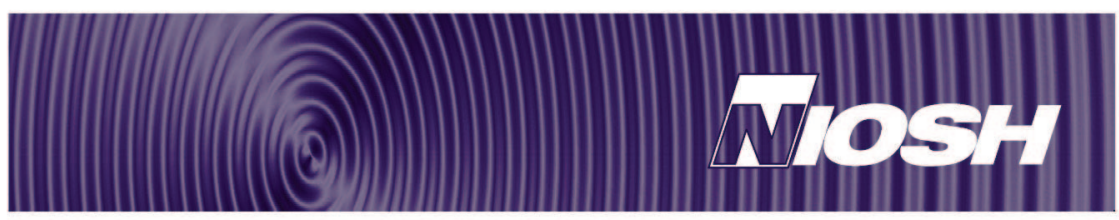


This document is in the public domain and may be freely copied or reprinted.

\section{Disclaimer}

Mention of any company or product does not constitute endorsement by NIOSH.

\section{Ordering Information}

To receive documents or more information about occupational safety and health topics, contact the National Institute for Occupational Safety and Health (NIOSH) at

NIOSH-Publications Dissemination 4676 Columbia Parkway

Cincinnati, OH 45226-1998

Telephone: 1-800-35-NIOSH (1-800-356-4674) Fax: 513-533-8573

E-mail: pubstaft@cdc.gov

or visit the NIOSH Web site at www.cdc.gov/niosh DHHS (NIOSH) Publication No. 2002-101 April 2002 


\section{Contents}

Introduction $\ldots \ldots \ldots \ldots \ldots \ldots \ldots$

What is workplace violence? . . . . . . . . . . . 1

Who is at risk? ................. 3

Where may violence occur? . . . . . . . . . . . 3

What are the effects of violence? . . . . . . . . . 3

What are the risk factors for violence? . . . . . . . . 4

Prevention Strategies for Employers . . . . . . . . 5

Environmental Designs............... 5

Administrative Controls . . . . . . . . . . . . 6

Behavior Modifications . . . . . . . . . . . 6

Dealing With the Consequences of Violence ..... 6

Safety Tips for Hospital Workers . . . . . . . . . 7

Summary ..................... 9

Bibliography.................... 9 


\section{About NIOSH}

As part of the Centers for Disease Control and Prevention (CDC), the National Institute for Occupational Safety and Health (NIOSH) conducts research and makes recommendations to prevent work-related illness and injury. NIOSH works with industries, labor organizations, and universities to understand and improve worker safety and health.

NIOSH is often confused with OSHA (the Occupational Safety and Health Administration). However, $\mathrm{NIOSH}$ and OSHA are separate agencies with different functions. NIOSH is a CDC research agency in the U.S. Department of Health and Human Services. OSHA is a regulatory agency in the U.S. Department of Labor. 


\section{Introduction}

Today more than 5 million U.S. hospital workers from many occupations perform a wide variety of duties. They are exposed to many safety and health hazards, including violence. Recent data indicate that hospital workers are at high risk for experiencing violence in the workplace. According to estimates of the Bureau of Labor Statistics (BLS), 2,637 nonfatal assaults on hospital workers occurred in 1999-a rate of 8.3 assaults per 10,000 workers. This rate is much higher than the rate of nonfatal assaults for all private-sector industries, which is 2 per 10,000 workers.

Several studies indicate that violence often takes place during times of high activity and interaction with patients, such as at meal times and during visiting hours and patient transportation. Assaults may occur when service is denied, when a patient is involuntarily admitted, or when a health care worker attempts to set limits on eating, drinking, or tobacco or alcohol use.

The purpose of this brochure is to increase worker and employer awareness of the risk factors for violence in hospitals and to provide strategies for reducing exposure to these factors.

\section{What is workplace violence?}

Workplace violence ranges from offensive or threatening language to homicide. NIOSH defines workplace violence as violent acts (including physical assaults and threats of assaults) directed toward persons at work or on duty. 
Examples of violence include the following:

Threats: Expressions of intent to cause harm, including verbal threats, threatening body language, and written threats.

Physical assaults: Attacks ranging from slapping and beating to rape, homicide, and the use of weapons such as firearms, bombs, or knives.

Muggings: Aggravated assaults, usually conducted by surprise and with intent to rob.

\section{Case Reports}

An elderly patient verbally abused a nurse and pulled her hair when she prevented him from leaving the hospital to go home in the middle of the night.

An agitated psychotic patient attacked a nurse, broke her arm, and scratched and bruised her.

A disturbed family member whose father had died in surgery at the community hospital walked into the emergency department and fired a small-caliber handgun, killing a nurse and an emergency medical technician and wounding the emergency physician.

These circumstances of hospital violence differ from the circumstances of workplace violence in general. In other workplaces such as convenience stores and taxicabs, violence most often relates to robbery. Violence in hospitals usually results from patients and occasionally from their family members who feel frustrated, vulner able, and out of control. 


\section{Who is at risk?}

Although anyone working in a hospital may become a victim of violence, nurses and aides who have the most direct contact with patients are at higher risk. Other hospital personnel at increased risk of violence include emergency response personnel, hospital safety officers, and all health care providers.

\section{Where may violence occur?}

Violence may occur anywhere in the hospital, but it is most frequent in the following areas:

- Psychiatric wards

- Emergency rooms

- Waiting rooms

- Geriatric units

\section{What are the effects of violence?}

The effects of violence can range in intensity and include the following:

- Minor physical injuries

- Serious physical injuries

- Temporary and permanent physical disability

- Psychological trauma

- Death

Violence may also have negative organizational outcomes such as low worker morale, increased job stress, increased worker turnover, reduced trust of management and coworkers, and a hostile working environment. 


\section{What are the risk factors for violence?}

The risk factors for violence vary from hospital to hospital depending on location, size, and type of care. Common risk factors for hospital violence include the following:

- Working directly with volatile people, especially if they are under the influence of drugs or alcohol or have a history of violence or certain psychotic diagnoses

- Working when understaffed-especially during meal times and visiting hours

- Transporting patients

- Long waits for service

- Overcrowded, uncomfortable waiting rooms

- Working alone

- Poor environmental design

- Inadequate security

- Lack of staff training and policies for preventing and managing crises with potentially volatile patients

- Drug and alcohol abuse

- Access to firearms

- Unrestricted movement of the public

- Poorly lit corridors, rooms, parking lots, and other areas 


\section{Prevention Strategies for Employers}

To prevent violence in hospitals, employers should develop a safety and health program that includes management commitment, employee participation, hazard identification, safety and health training, and hazard prevention, control, and reporting. Employers should evaluate this program periodically.

Although risk factors for violence are specific for each hospital and its work scenarios, employers can follow general prevention strategies.

\section{Environmental Designs}

- Develop emergency signaling, alarms, and monitoring systems.

- Install security devices such as metal detectors to prevent armed persons from entering the hospital.

- Install other security devices such as cameras and good lighting in hallways.

- Provide security escorts to the parking lots at night.

- Design waiting areas to accommodate and assist visitors and patients who may have a delay in service.

- Design the triage area and other public areas to minimize the risk of assault:

- Provide staff restrooms and emergency exits. 
- Install enclosed nurses' stations.

- Install deep service counters or bulletresistant and shatterproof glass enclosures in reception areas.

- Arrange furniture and other objects to minimize their use as weapons.

\section{Administrative Controls}

- Design staffing patterns to prevent personnel from working alone and to minimize patient waiting time.

- Restrict the movement of the public in hospitals by card-controlled access.

- Develop a system for alerting security personnel when violence is threatened.

\section{Behavior Modifications}

- Provide all workers with training in recognizing and managing assaults, resolving conflicts, and maintaining hazard awareness.

\section{Dealing With the Consequences of Violence}

Violence may occur in the workplace in spite of preventive measures. Employers should be prepared to deal with the consequences of this violence by providing an environment that promotes open communication and by developing written procedures for reporting and responding to violence. Employers should offer and encourage counseling whenever a worker is threatened or assaulted. 


\section{Safety Tips for Hospital Workers}

Watch for signals that may be associated with impending violence:

- Verbally expressed anger and frustration

- Body language such as threatening gestures

- Signs of drug or alcohol use

- Presence of a weapon

\section{Maintain behavior that helps diffuse anger:}

- Present a calm, caring attitude.

- Don't match the threats.

- Don't give orders.

- Acknowledge the person's feelings (for example, "I know you are frustrated").

- Avoid any behavior that may be interpreted as aggressive (for example, moving rapidly, getting too close, touching, or speaking loudly).

\section{Be alert:}

- Evaluate each situation for potential violence when you enter a room or begin to relate to a patient or visitor.

- Be vigilant throughout the encounter.

- Don't isolate yourself with a potentially violent person.

- Always keep an open path for exiting-don't let the potentially violent person stand between you and the door. 


\section{Take these steps if you can't defuse the situation quickly:}

- Remove yourself from the situation.

- Call security for help.

- Report any violent incidents to your management.

\section{Case Reports: Prevention Strategies That Have Worked}

A security screening system in a Detroit hospital included stationary metal detectors supplemented by hand-held units. The system prevented the entry of 33 handguns, 1,324 knives, and 97 mace-type sprays during a 6-month period.

A violence reporting program in the Portland, Oregon, VA Medical Center identified patients with a history of violence in a computerized database.* The program helped reduce the number of all violent attacks by $91.6 \%$ by alerting staff to take additional safety measures when serving these patients.

A system restricting movement of visitors in a New York City hospital used identification badges and color-coded passes to limit each visitor to a spe cific floor. The hospital also enforced the limit of two visitors at a time per patient. Over 18 months, these actions reduced the number of reported violent crimes by $65 \%$.

*Health information and the electronic recording of this information must comply with appliscable Federal standards on privacy under Titles 42 and 45 of the U.S. Code. 


\section{Summary}

All hospitals should develop a comprehensive violence prevention program. No universal strategy exists to prevent violence. The risk factors vary from hospital to hospital and from unit to unit. Hospitals should form multidisciplinary committees that include direct-care staff as well as union representatives (if available) to identify risk factors in specific work scenarios and to develop strategies for reducing them.

All hospital workers should be alert and cautious when interacting with patients and visitors. They should actively participate in safety training programs and be familiar with their employers' policies, procedures, and materials on violence prevention.

\section{Bibliography}

AMA [1995]. Violence in the medical workplace: prevention strategies. Chicago, IL: American Medical Association.

Felton JS [1997]. Violence prevention at the health care site. Occup Med: State of the Art Reviews 12(4):701715 .

Goodman RA, Jenkins EL, Mercy JA [1994]. Workplace-related homicide among health care workers in the United States, 1980 through 1990. JAMA 272(21):1686-1688.

Lipscomb J [1994]. Violence in the health care industry: greater recognition prompting occupational health and safety interventions. In: Charney W, ed. Essentials of modern hospital safety. Vol. 3. Boca Raton, FL: Lewis Publishers, pp. 29-104. 
Lipscomb J [1999]. Violence in the workplace: a growing crisis among health care workers. In: Charney W, Fragala G, eds. The epidemic of health care worker injury. Boca Raton, FL: CRC Press, pp.163-165.

NIOSH [1996]. Current intelligence bulletin 57: violence in the workplace; risk factors and prevention strategies. Cincinnati, OH: U.S. Department of Health and Human Services, Public Health Service, Centers for Disease Control and Prevention, National Institute for Occupational Safety and Health, DHHS (NIOSH) Publication No. 96-100.

OSHA [1996]. Guidelines for preventing workplace violence for health care and social service workers. Washington, DC: U.S. Department of Labor, Occupational Safety and Health Administration, OSHA 31481996.

Simonowitz JA [1996]. Health care workers and workplace violence. Occup Med: State of the Art Reviews 11(2):277-291.

Turner JT, ed. [1984]. Violence in the medical care setting: a survival guide. Rockville, MD: Aspen Systems Corporation. 
